\title{
A experiência da natureza como processo de inventividade
}

\author{
Sabina Couto \\ Domingos Loureiro \\ Universidade do Porto
}

\begin{abstract}
Resumo
O artigo apresenta, de forma resumida, um projeto de investigação vocacionado para a experiência da natureza como estímulo à criatividade. É aqui refletido sobre a relação com a natureza e da experiência do contato direto que manifesta um potencial que as experiências simbólica e indireta não conseguem proporcionar. Este contato direto para além de fortalecer a conexão com a natureza e elevar o bem-estar, também aumenta a curiosidade e inventividade. Esta investigação reúne um conjunto de estudos que indicam a natureza capaz de evocar o pensamento criativo, tornando uma pessoa mais flexível na forma de pensar e mais apta para conseguir novas ideias. Procura perceber-se como auxilia na restauração da atenção direcionada, fundamental na avaliação e evolução das ideias. Por último, são mencionadas práticas artísticas que fundamentam esta questão da natureza como promotor criativo.
\end{abstract}

Palavras-chave: Arte. Experiência. Natureza. Inventividade.

\section{Introdução}

Observa-se que tendências como a contínua exploração dos recursos, a ampliação da malha urbana, a proliferação química, têm promovido a carência de biodiversidade e, como consequência, a quebra da qualidade e do contacto $^{1}$ do humano com a natureza. Segundo Heesoon Bai (2015), esta carência está a pôr em risco, bases do desenvolvimento mental e físico das crianças, referindo que atualmente e de forma generalizada, grande parte das crianças crescem sem sentirem contacto direto com a natureza, nomeadamente, de sentir o solo da floresta com os próprios pés. Mesmo que os pais tenham origens de um meio rural, as conceções que estes formulam do contacto e da natureza é rudimentar, e ensinam as crianças indiretamente e de forma explícita que a natureza é primitiva, perigosa e que apenas tem valor como recurso económico. Afirma ainda, que as crianças são urbanizadas e ensinadas a encarar a natureza como algo que deve ser destruído em prol da civilização (BAI et al., 2015). Assim, as crianças vivem afastadas do mundo natural e as suas experiências,

\footnotetext{
${ }^{1}$ Nota do Editor. A revista ARJ - Art Research Journal preserva a grafia original em português de Portugal. As recomendações da Associação Brasileira de Normas Técnicas são observadas parcialmente.
} 
habitualmente, decorrem nos meios de comunicação ou através de imagens (WHITE, 2004). A criança desfruta de um vasto acesso de informações e imagens da natureza que apenas fornecem experiências de forma indireta, o que que nunca terá o mesmo efeito emocional e sensorial que o contato direto, como a descoberta do que está em baixo de uma pedra no rio ou a sensação de subir a uma árvore, ou a paz espiritual que se sente quando se está apenas a observar (FINCH; BAILIE, 2015).

A experiência do contato direto com a natureza manifesta potencial que as experiências simbólica e indireta não conseguem proporcionar. Do ponto de vista de Kellert (2002), este contato direto para além de fortalecer a conexão com a natureza e elevar o bem-estar, também aumenta a curiosidade e invenção. As crianças que têm oportunidade de viver experiências na natureza sentem um complexo de emoções, como de alegria, satisfação e simultaneamente de desafio, ansiedade e medo. O espaço exterior e, sobretudo a natureza suscita entusiasmo e prazer, mas, por outro lado, um sentimento de incerteza, risco e, por vezes, temor. Essas vivências diretas conferem imensas oportunidades emocionais, de revelação e de inventividade (KELLERT, 2005). Igualmente, Wendy Banning, considera que o contato direto com a natureza pode proporcionar às crianças o desenvolvimento de aptidões e de pensamento criativo que perdurarão ao longo da vida (BANNING; SULLIVAN, 2010). De acordo com o pintor naturalista Robert Bateman (1930 -) as crianças são cativadas naturalmente pelas plantas, árvores e rios. Também, Helen Tovey (1921 - 2019) refere que, as crianças, quando têm a possibilidade de escolha optam pelos espaços naturais onde podem vivenciar algo imprevisível, misterioso, excitante e viver momentos de aventura (TOVEY, 2007). Por esse motivo, assume-se que as crianças nascem com grande probabilidade de se tornarem apreciadores da natureza, repletos de admiração e curiosidade. Seguindo este pensamento, ensiná-las a adquirirem sensibilidade e valores referentes à natureza não é apresentar algo que lhes será totalmente novo (BAl et al., 2015).

\section{Natureza e inventividade}

A investigação em torno do contato direto com a natureza revela evidências de que a experiência na natureza influencia a criatividade e certas culturas consideram que existe um vínculo especial entre natureza e criatividade. Nesse contexto, foram efetuados estudos promissores que procuraram pôr à prova a relação entre natureza e inventividade que manifestaram de forma consistente um aumento mediante o contato com ambientes naturais ou elementos naturais em meios construídos.

Dois ensaios revelam benefícios do contato com a natureza, nomeadamente: o ensaio realizado pelo investigador e professor de psicologia na Universidade do Utah, David Strayer, e pelos cientistas Ruth Ann Atchley e Paul Atchley da Universidade do Kansas. Este ensaio publicado na revista PLOS ONE, da Public Library of Science (2012) resulta de uma 
investigação sobre os efeitos da exposição prolongada em ambientes naturais e surge como primeira tentativa de analisar as alterações no desenvolvimento cognitivo de ordem mais elevada dessa extensa exposição (SIC NOTÍCIAS, 2012). O teste cognitivo de ordem superior utilizado foi o "Remote Associates Test" (RAT) concebido pelo professor/investigador Sarnoff Andrei Mednick (1928 - 2015) substancialmente utilizado como uma avaliação de raciocínio criativo e de resolução de problemas (MEDNICK, 1962). Este teste consiste em três palavras (tríades), e o exercício é escrever uma quarta palavra como resolução que esteja associada às três palavras (por exemplo, Cair, Ator, Pó/ solução = estrela).

O estudo foi realizado com cinquenta e seis pessoas (vinte e seis mulheres e trinta homens) com média de vinte e oito anos que participam em expedições realizadas pela organização sem fins lucrativos, Outward Bound, em áreas naturais com reduzida intervenção humana. O projeto consistia em oito grupos de caminhadas divididos aleatoriamente pela metade, sendo uma parte designada para o grupo de pré-caminhada e outra parte para o grupo de caminhada. No grupo de pré-caminhadas, oito foram pela natureza do Alasca, dez pelo Colorado e seis pela região do Maine; e nos grupos de caminhadas, nove no Alasca, catorze pelo Colorado e nove pela região de Washington. A experiência foi realizada durante quatro a seis dias, apenas com uma mochila às costas, sem comunicação entre os vários grupos e sem qualquer uso de tecnologias. Então, o grupo de pré-caminhada era composto por vinte e quatro participantes (onze mulheres com idade média de trinta e quatro anos) e o grupo de caminhada composto por trinta e dois participantes (quinze mulheres com idade média de vinte e quatro anos). Visto que a idade interfere na atividade, esta foi considerada como uma variável nas análises posteriores. Prosseguindo, o grupo de pré-caminhada terminou o RAT na manhã antes de começar a viagem e o grupo em caminhada terminou o RAT na manhã do quarto dia ou durante o percurso. Todos os intervenientes tiveram um tempo ilimitado para finalizar as dez perguntas do teste e de modo independente, sem colaboração entre os participantes, como foi comprovado tanto pela análise de respostas como o indicado pela Outward Bound (ATCHLEY; STRAYER; ATCHLEY, 2012). Os resultados indicaram que os intervenientes que tiveram os quatro dias na natureza acertaram uma média de 6,08 questões, enquanto os outros participantes apenas conseguiram 4,14 respostas certas. Como referem os autores, a certo momento, no artigo:

when our research participants spent four days in a natural setting, absent all the tools of technology, the surrounding natural setting allowed them to bring a wide range of cognitive resources to bear when asked to engage in a task that requires creativity and complex convergent problem solving. (ATCHLEY; STRAYER; ATCHLEY, 2012, p.2).

Este estudo revelou que as funções cerebrais associadas à criatividade e a resolução de problemas são estimuladas quando há uma conexão com a natureza. $\mathrm{E}$, continuando esta 
linha de pensamento, temos o estudo concretizado pelo professor de psicologia e investigador, Frank M. Ferraro III, da Universidade de Nebrasca.

The purpose of the current study was to investigate whether nature immersion can improve an objective and convergent measure of creativity, as opposed to divergent, artistic, or self-assessed creative processes (Ferraro III, 2015, p.8). (ATCHLEY; STRAYER; ATCHLEY, 2012, p.2).

Apesar de se basear no ensaio de Atchley et al. (2012) implementou um grupo de controlo interno (sala de aula) de comparação entre sujeitos, o que não acontecia no estudo referido anteriormente. Partindo desse estudo, Ferraro III (2015) pressupôs que estudantes do ensino superior após viajarem seis dias ao ar livre, no meio da natureza, iriam obter respostas com um nível de criatividade superior em comparação com estudantes testados unicamente no espaço da sala de aula (grupo interno). O ensaio era constituído por vinte e cinco estudantes de uma Universidade privada, dos quais vinte e dois eram caucasianos, um afro-americano, um asiático e um latino. Os estudantes (onze) que pertenciam ao grupo ao ar livre estavam inscritos no primeiro ano do curso de seminário sobre natureza selvagem e os estudantes (catorze) do grupo interno inscritos no primeiro ano do curso de seminário de psicologia anómala. Ambos os grupos realizaram o RAT como sucedeu no ensaio de Atchley et al. (2012) do qual detiveram de dez minutos para responder a dez questões, mas antes realizaram um pré-teste. Este pré-teste do RAT (itens aleatórios e diferentes do estudo) foi concretizado pelos dois grupos numa sala da Universidade comum para ficarem familiarizados com as condições do respetivo teste. Os resultados do pré-teste apresentaram claramente poucas diferenças entre os dois grupos (externo e interno). Relativamente ao teste fundamental (RAT), o grupo que esteve na natureza responderam às questões no final da viagem de seis dias, no exterior, perto de um lago, Boundary Waters Canoe Area Wilderness (BWCAW). O outro grupo, constituído pelos estudantes internos concretizaram também o teste seis dias após o pré-teste, de forma a coincidir com a sequência temporal do grupo externo (FERRARO III, 2015). O conjunto de dados indicou que o grupo externo teve pontuações de cinco a dez itens corretos com média de sete, enquanto que o grupo interno obteve de um a sete com uma média de seis. Os resultados do teste:

[...] indicate multiday wilderness experiences may aid convergent creativity ability. A significant increase in creativity (measured by selected items from the RAT) was found in first year students completing a BWCAW trip compared to an indoor control group. Interestingly, the percentage increase [...] seen in the current study $(49 \%)$ is similar to the cognitive improvement published by Atchley et al. (2012), showing nearly a $47 \%$ increase in RAT scores in an outdoor hiking condition. [...] A strength of the current study is that pretest creativity scores for both the indoor and outdoor groups were not significantly different. Only after a multiday wilderness experience did the outdoor group show a significant increase in correct RAT items, establishing temporal precedence of the nature effect. (FERRARO III, 2015, p.9). 
Esta experiência influenciou diretamente o aumento de inventividade e produziu benefícios psicológicos e cognitivos. De acordo com o autor, a imersão na natureza pode ser um método para potenciar a criatividade em jovens adultos. Considera ainda, que estas revelações atuais devem ser aprofundadas para compreender como a natureza pode proporcionar uma melhoria das experiências dos estudantes do ensino superior (FERRARO III, 2015).

Outras investigações testaram o efeito da experiência da natureza na criatividade e destacaram caraterísticas dessa relação para compreender como esta sucede. Um exemplo, o estudo publicado na revista Urban Forestry \& Urban Greening (2015) por Trina Plambech gerente da Alexandria Institute, em Copenhaga e pelo professor Cecil C. Konijnendijk van den Bosch do Departamento de Arquitetura Paisagista, da Universidade Sueca de Ciências Agrícolas. O objetivo do estudo: avaliar o papel da natureza no processo criativo a partir de entrevistas a profissionais dinamarqueses que trabalham em áreas criativas, como artes e "design". Recorreram ao método de entrevistas qualitativas semiestruturadas direcionadas a dezassete profissionais de áreas diferentes, dos quais oito eram homens entre os trinta e quatro e os setenta e três anos, e nove mulheres entre os vinte e oito e os cinquenta e sete anos. Sendo pretendido verificar a criatividade, a relação com a natureza e determinar a capacidade da experiência da natureza em estimular a inventividade nestes profissionais. As entrevistas foram realizadas durante o verão de 2012 por telemóvel ou via Skype durante aproximadamente uma hora e dividiu-se em duas fases: primeiro, compreender o que é para os entrevistados a criatividade, a sua experiência, assim como a importância dos lugares para a valorização da inventividade. Nesta fase, o interesse era explorar a criatividade dos intervenientes, em geral, antes de serem questionados acerca da influência da natureza; segundo, um conjunto de perguntas direcionadas ao conhecimento que têm da natureza, quais os tipos de natureza que preferem e qual a importância que esta tem na vida deles. Esta fase destinou-se a compreender a relação entre a natureza e a criatividade (PLAMBECH; VAN DEN BOSCH, 2015).

Durante as entrevistas, os participantes descreveram a experiência e os aspetos positivos do tempo que despenderam na natureza, especificamente: restaurar energia para as atividades criativas; transmitir calma e proporcionar mais ideias; e maior capacidade para sintetizar e organizar ideias.

The respondents explained how nature makes them more curious with an awakened desire to explore. In nature there is an infinite variety. The same place is never the same. Being in nature is intriguing, it makes one wonder and it is fascinating. (PLAMBECH; VAN DEN BOSCH, 2015, p. 259)

Verificou-se que parte dos profissionais se deslocavam até à natureza para recolher ideias e inspiração através da observação das formas, cheiros e sons. Regularmente a 
experiência da natureza comummente impulsionava o processo da criatividade, ou seja, a natureza concedia uma espécie de descanso da preparação exaustiva de uma tarefa inventiva. Por essa razão, restabelece a aptidão de direcionar o foco indispensável para determinadas atividades durante duas fases posteriores do desempenho produtivo: criar e avaliar ideias. Isto é, a natureza tem a aptidão de evocar o pensamento criativo, tornando uma pessoa mais flexível na forma de pensar e mais apta para conseguir novas ideias. Além disso, auxilia na restauração da atenção direcionada, essencial na avaliação e evolução das ideias (PLAMBECH; VAN DEN BOSCH, 2015). Os resultados indicam que a natureza presenteia com dimensões sensoriais que revelam ser de especial importância para os processos criativos e por isso, é uma mais valia ter acesso a diferentes ambientes naturais.

Em geral, os dados registaram alterações coerentes na função cognitiva a nível superior, associados à exposição prolongada na natureza. De acordo com os resultados do estudo Atchley et al. (2012), após quatro dias no meio natural apresentaram uma elevada gama de recursos cognitivos e aumento de criatividade. Igualmente, o ensaio de Ferraro III (2015) evidenciou que a experiência direta da natureza reforçou a inventividade e proporcionou benefícios psicológicos e cognitivos. Neste sentido, outros estudos indicaram que a imersão na natureza pode ser um método para potenciar a criatividade (PLAMBECH; VAN DEN BOSCH, 2015). Portanto, a experiência da natureza de forma continuada pode impulsionar o processo de inventividade, através da recolha de ideias e inspiração que surge da observação.

\section{Práticas artísticas}

Em relação ao potencial do estímulo criativo e à valorização da imaginação, a natureza é constantemente uma referência em diversas áreas, como a literatura, música, arquitetura e artes visuais. Se refletirmos sobre as artes visuais, por exemplo, podemos encontrar artistas que usam matérias provenientes diretamente da natureza e que reconhecem o valor dos materiais orgânicos e encontram o estímulo criativo no mundo natural. O trabalho em contexto exterior, numa multiplicidade de estratégias, visuais, fenomenológicas, contextuais, entre outras, é também frequente. É o caso das práticas da "Land Art" que surgiu na década de 60 nos Estados Unidos e na Europa, na qual os artistas recorrem a materiais provenientes da natureza e trabalham diretamente no próprio local. Neste contexto, temos o artista Richard Long (1945 -) que utiliza materiais naturais e estabelece uma relação direta entre o seu corpo e essas matérias. Trabalha questões relativas à escala, a forma como se move e interage com os lugares e os seus elementos (figura 1). Os espaços selecionados são zonas com aspeto selvagem que não pretende apropriar-se delas, mas antes uma espécie de marca pessoal da sua caminhada que pelo tempo se apaga (LONG, 1994). 


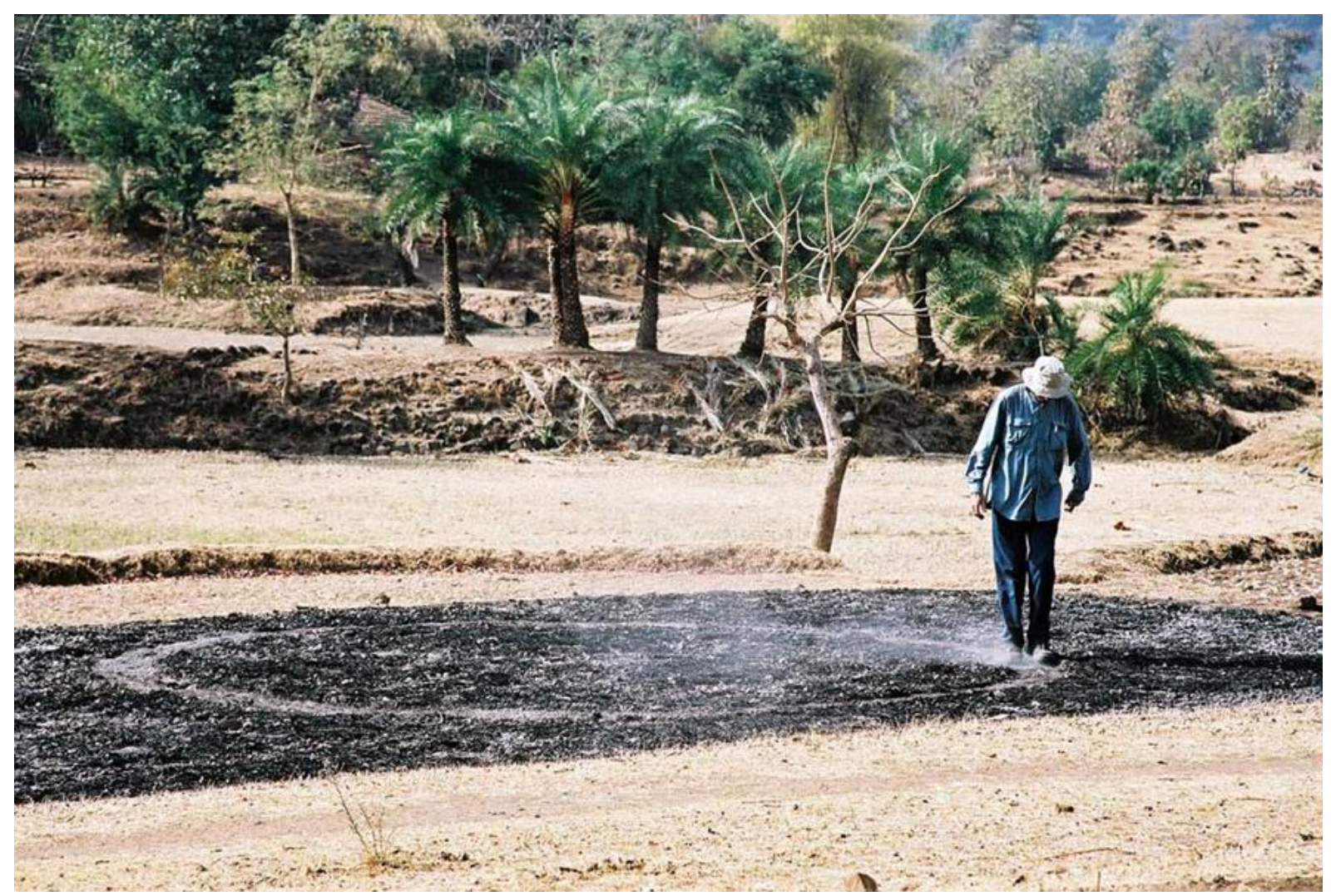

Figura 1 - Richard Long, A Walking and Running Circle, Warli Tribal Land Maharashtra, India, 2003 (fonte: http://www.richardlong.org/Sculptures/2011sculpupgrades/walkrun2.html)

Se pensarmos na música, temos a "Grand Canyon Suite" do compositor Ferde Grofée (1892 - 1972), em que a viagem ao deserto de Arizona para observar o pôr do sol sobre o Grand Canyon surge como base de inspiração criativa. A forma como os elementos da natureza interagem, o silêncio e o som dos pássaros, das gotas a cair ou vento nas árvores (SCHIAVONE, 2000). São tudo possibilidades de inspiração para criar diversas melodias na música. Quanto à arquitetura temos as obras do arquiteto Antoní Gaudí (1852 - 1926) que devido a problemas de saúde desde criança passava o tempo a dedicar-se à observação minuciosa das formas e dinâmicas da natureza, aos detalhes de cada ramo, folhas, frutos ou insetos. A partir destas experiências da natureza encontrou a inspiração e criatividade para as suas obras, como: a Casa Milá (La Pedrera) construída entre 1905 e 1907; e a "Sagrada Família" com início de construção em 1826 e data prevista de conclusão em 2026. O interior deste edifico é inspirado na floresta, sendo constituída por colunas que se assemelham a árvores e que se ramificam no teto (figura 2). Gaudí encontrou na contemplação da natureza o estimulo criativo que o ajudou a projetar obras com um estilo único e individual (MODESTO, 2014). 


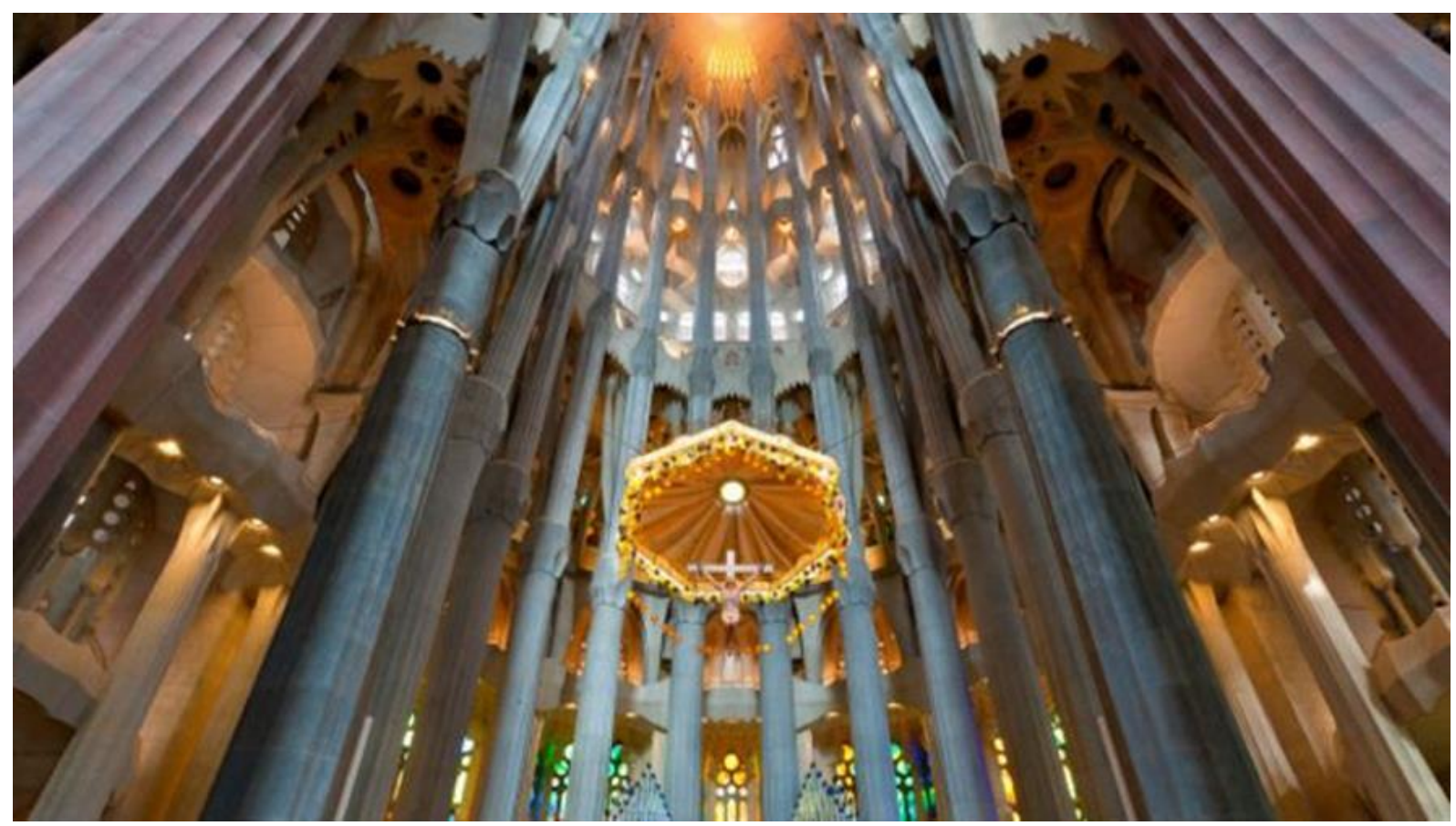

Figura 2 - Antoní Gaudí, detalhe da Catedral da Sagrada Família, Barcelona, fotografia de John Kellerman Alamy (fonte:

https://www.bbc.com/portuguese/noticias/2015/09/150921_vert_earth_arquitetura_natureza_ml)

E, continuando sobre o potencial da natureza como estímulo criativo, temos a obra do artista alemão Mario Reis (1953 - ) que realizou ao longo do seu percurso o projeto "Nature Watercolors" (figura 3), no qual a natureza se expressa diretamente sobre uma superfície horizontal e deixa as suas marcas. Estes trabalhos sucedem do interesse pela natureza, expressividade da água e:

unstable character of water, as well as the fact that we are deeply connected with water anyway. Water always changes, by nature. Sometimes it is fluid, sometimes gas or solid. Water is able to carve deep canyons out of the hardest rock. (Mario Reis citado em Grande, 2014, p.115).

Reis aborda a natureza diretamente e instala telas no leito de diversos rios por todo o mundo, possibilitando que os resíduos vegetais e minerais se acumulem na superfície do suporte. As telas ficam durante vários dias no local e o resultado é obtido através da força e mudanças da natureza que vão ocorrendo (GRANDE, 2004). Aqui a água surge como pincel que cria uma grande variedade de padrões, texturas e cores de acordo com espaço escolhido pelo artista. 


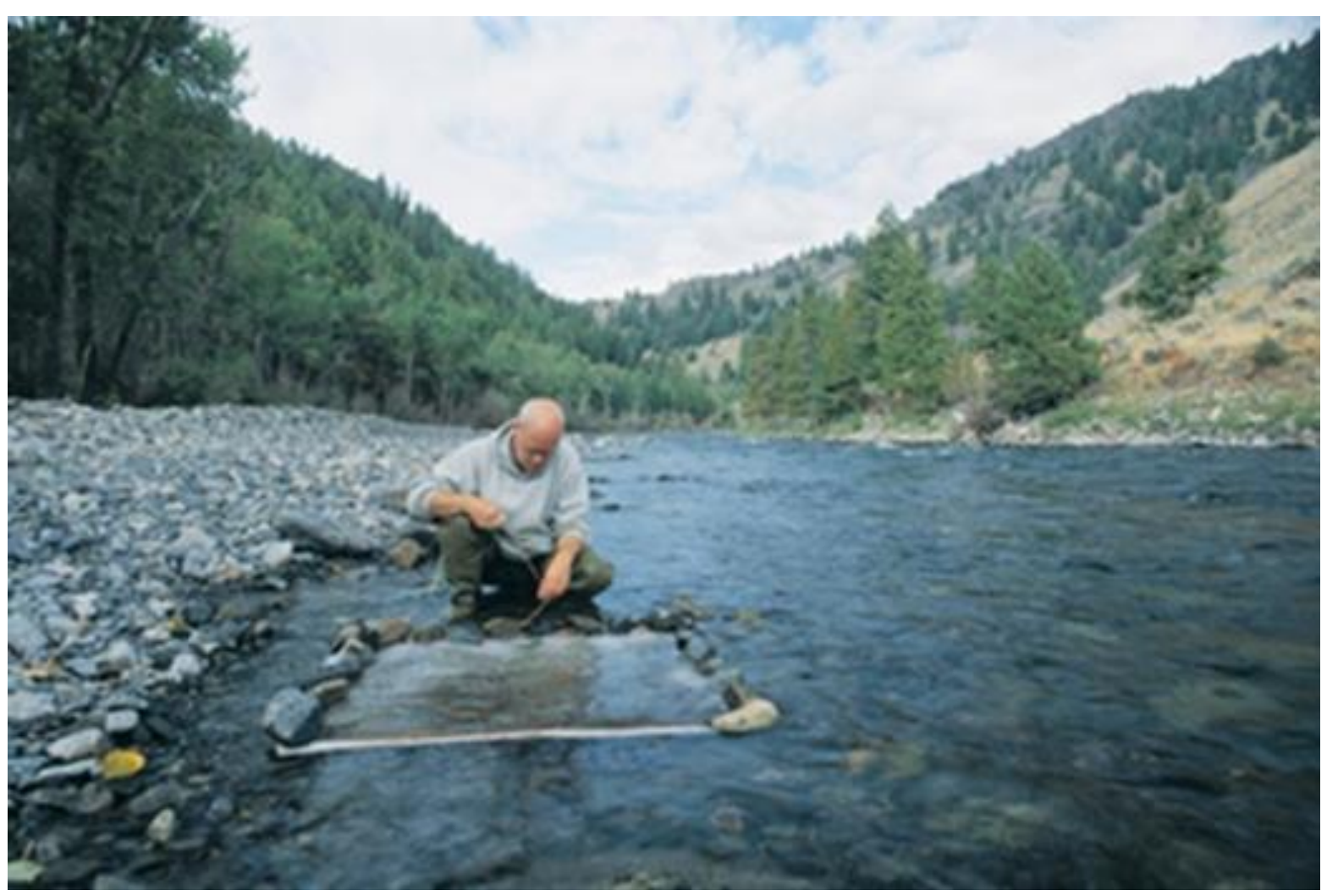

Figura 3 - Mario Reis, fotografia do processo de trabalho, projeto Nature - Watercolors (fonte: http://www.marioreis.de/)

Também, o artista português Alberto Carneiro (1937 - 2017) descobre na natureza o impulso criativo e cada material que escolhe do meio natural tem que ver com a energia que este consegue observar e identificar na matéria. Trabalha com árvores e madeira, mas ao trabalhar com este material procura descobrir novamente a árvore que existe nela, a energia e a essência da vida da árvore (AMARANTE, 2015). A obra surge a partir da experimentação, da conexão e reflexão com a natureza e desenvolve-se a partir de uma relação estética com as suas árvores e flores, ou seja, da sua vivência íntima com estes elementos e orienta-o na criação artística (figura 4). Assim, Carneiro refere:

O meu interesse pela utilização da natureza como matéria na obra tem a ver com a consciência ou a busca de que o fundamental é a energia que sai das coisas e que circula entre elas. [...] a minha própria identificação com o que eu tinha vivido, numa relação direta com os materiais e matérias da terra. Naturalmente, há uma relação vivida com a natureza [...] (Alberto Carneiro, citado em AMARANTE, 2015, p. 23) 


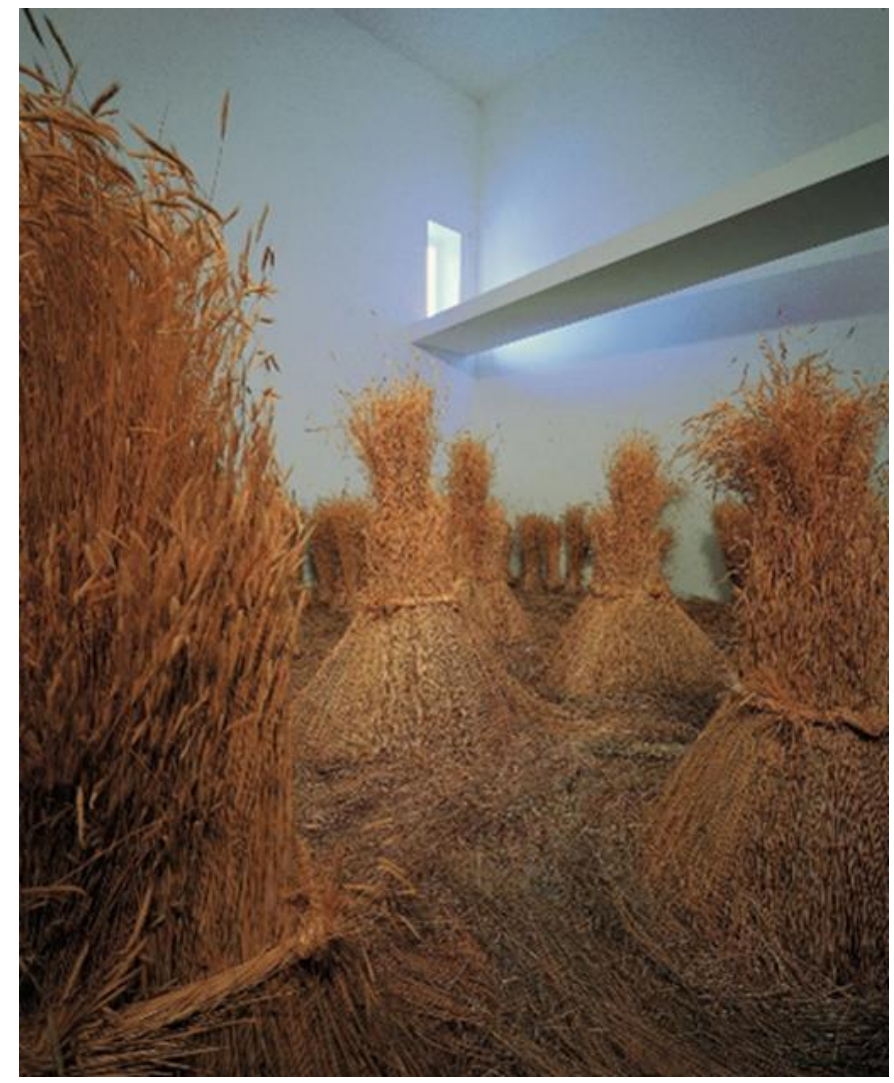

Figura 4 - Alberto Carneiro, um campo depois da colheita para deleite estético do nosso corpo, 1976 (fonte:

https://www.wikiart.org/en/albertocarneiro/um-campo-depois-da-colheitapara-deleite-est-tico-do-nosso-corpo1976)

Outro exemplo, são as instalações com elementos vegetais do belga Bob Verschueren (1945 -) como folhas, galhos e frutos. Os materiais são selecionados de acordo com a sua forma e cor, na qual mantém a sua estrutura própria e organiza de modo bastante preciso quase como geométrico (GRANDE, 2004). Observa atentamente as estruturas dos elementos vegetais e as formas surgem a partir de cortes rigorosos e previamente marcados (figura 5). Antes do início da sua concretização estabelece um princípio base, evitar ao máximo o uso de cordas ou outros meios técnicos, ou seja, eliminar ao máximo qualquer elemento não vegetal, abrindo exceções apenas quando necessário. Este interesse por explorar os elementos da natureza ocorreu:

by accident [...] Feeling the need to explore other paths, I went outside, and I there met nature. It left a strong impression on me. [...] then used leaves because [...] leaves are easy to carry, in autumn they change color and create a large carpet on the ground. What fascinated me with this material was its constant transformation, both in color and form. When one brings this leafy material into an interior space, we see it anew. Installed out of their natural context, leaves are free from any of the usual associations we have with them. [...] The work changes and moves, just like a living being. (Bob Verschueren, citado em GRANDE, 2014, p. 84).

Verschueren explorou os sons das plantas no Banff Center for the Arts e apresentou extensivamente as suas fotografias e instalações na Europa, assim como no Japão e América do Norte. O trabalho deste artista invoca uma abordagem fenomenológica e em cada projeto 
aplica elementos naturais para criar uma relação com a paisagem e a arquitetura de cada local, seja em espaços interiores, na natureza ou na cidade.

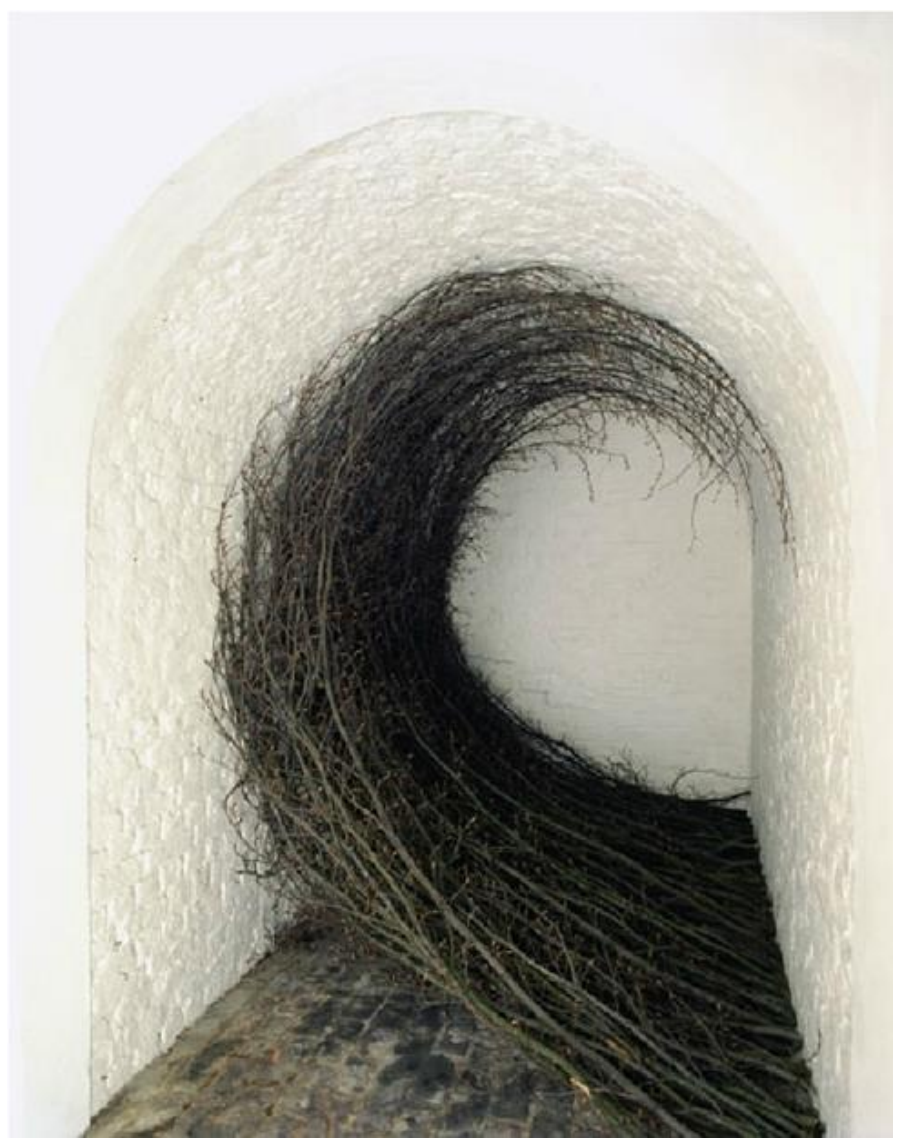

Figura 5 - Bob Verschueren, Installation I, 2002, ramos de faia, Galerie Usagexteme, Bruxelas (fonte: http://www.bobverschueren.net/ DimensionSupplementaireEng.html)

As práticas artísticas aqui expostas, permitem reconhecer a natureza com um elevado potencial de estímulo criativo e como uma constante referência em diversos âmbitos. Ainda que o meio natural tenha assumido um papel fundamental em todas as obras mencionadas, para cada autor a natureza e a posição que esta assume no processo criativo, é diferente. Por exemplo, a "Grand Canyon Suite" do compositor Ferde Grofée que encontrou na caminhada e na contemplação do pôr do sol a inspiração para criar as melodias; e Antoní Gaudí, em que a natureza surge nos seus projetos mediante a observação constante e detalhada de todos os elementos que o rodeava. No caso de Richard Long, Mario Reis, Bob Verschueren e Alberto Carneiro recorrem à recolha das matérias diretamente da natureza, que vão pertencer à obra e interferem diretamente, contudo, são inspirados de formas distintas. Long, opta por zonas selvagens e não se apropria, somente deixa a sua marca, quando se move e interage com os lugares e os seus materiais. Em relação ao trabalho de Reis, este elege a água como elemento que deixa marcas e vestígios nos seus trabalhos, sendo esta o seu pincel. Comparativamente, Verschueren, os elementos naturais (folhas, ramos e frutos) são eleitos pela semelhança ao ciclo da vida, que vão mudar de cor e de 
estado. Relativamente a Carneiro, existe uma relação profunda com a natureza, em especial com as terras da sua infância e a árvore, em procura a energia e a essência.

Por último, compreendida a configuração do meio natural nos casos referidos previamente, é significativo reconhecer de que modo estas experiências diretas, torna os artistas mais inventivos. Assim sendo, a natureza permite restaurar a energia e proporcionar uma espécie de descanso que auxilia para uma tarefa inventiva, como conceber o projeto do interior da Catedral da "Sagrada Família". Neste aspeto, a calma transmitida proporciona maior capacidade para sintetizar e organizar, como aptidão de direcionar o foco (restauração da atenção) e mais flexibilidade. Além disso, as variedades infinitas geram curiosidade e mais ideias, em que as dimensões sensoriais são exploradas (PLAMBECH; VAN DEN BOSCH, 2015). Por essas razões, os artistas que imergem na natureza têm as funções cerebrais associadas à criatividade e a resolução de problemas mais estimulados (ATCHLEY; STRAYER; ATCHLEY, 2012). Tal como, benefícios psicológicos e cognitivos (FERRARO III, 2015) que potencia a inventividade.

\section{Em modo de conclusão}

Observamos nesta investigação, com base nos ensaios mencionados, que a experiência direta com a natureza influencia o processo criativo. Como revelou o estudo realizado por David Strayer, Ruth Ann Atchley e Paul Atchley que as funções cerebrais associadas à criatividade e à resolução de problemas são estimuladas quando há uma conexão com a natureza. Os resultados deste estudo indicaram que os intervenientes que tiveram os quatro dias na natureza acertaram uma média de 6,08 questões, enquanto os outros participantes apenas conseguiram 4,14 respostas certas. Prosseguindo, também o ensaio de Ferraro III indicou que parte dos profissionais se deslocavam até à natureza para recolher ideias e inspiração através da observação das formas, cheiros e sons. Regularmente a experiência da natureza de forma continuada impulsionava o processo da criatividade, ou

seja, a natureza concedia uma espécie de descanso da preparação exaustiva de uma tarefa inventiva. Por essa razão, restabelece a aptidão de direcionar o foco indispensável para determinadas atividades durante duas fases posteriores do desempenho produtivo: criar e avaliar ideias. Por outras palavras, a natureza tem a aptidão de evocar o pensamento criativo, potenciando que a pessoa se torne mais flexível na forma de pensar e mais apta para conseguir novas ideias. Além disso, auxilia na restauração da atenção direcionada, fundamental na avaliação e evolução das ideias.

Os resultados apontam que a natureza presenteia com dimensões sensoriais que revelam ser de especial importância para os processos criativos. Por isso, a natureza tem um elevado potencial para estimular a inventividade e imaginação, e a música "Grand Canyon Suite" do compositor Ferde Grofée; a "Sagrada Família" de Gaudí; a "Nature watercolors" de 
Mario Reis; a instalações de Bob Verschueren; a relação de Richard Long com os lugares/materiais; e "um campo depois da colheita para deleite estético do nosso corpo" de Alberto Carneiro, apenas são algumas ilustrações do poder da natureza como promotora criativa.

Portanto, este artigo dá-nos indicações sobre a importância da relação da experiência com a natureza e a sua capacidade de evocar o pensamento criativo. Contudo, neste caso, futuramente interessa perceber quais os impactos destes processos no caso particular das crianças. Como referido anteriormente, a relação do homem com a natureza revela vantagens em vários aspetos e seguindo esse pensamento, poderá ser mais eficaz em contexto das crianças, que será o alvo da investigação seguinte.

\section{Referências}

AMARANTE [Câmara Municipal de Amarante]. Alberto Carneiro: Grande Prémio Amadeu de SousaCardoso. [S. I.], 2015.

ATCHLEY, Ruth Ann; STRAYER, David L.; ATCHLEY, Paul. Creativity in the Wild: Improving Creative Reasoning through Immersion in Natural Settings. PLOS ONE, 7(12), p. 10-13, 2012.

BAI, Heesoon; ELZA, Daniela; KOVACS, Peter; ROMANYCIA, Serenna. Re-searching and re-storying the complex and complicated relationship of biophilia and bibliophilia Re-searching and Re-storying the Complex and Complicated Relationship of Biophilia and Bibliophilia. Environmental Education Research, [s. I.], 16(3), 351-365, 2010. Disponível em: https://www.researchgate.net/publication/248965513_Re-searching_and_restorying_the_complex_and_complicated_relationship_of_biophilia_and_bibliophilia

BANNING, Wendy; SULLIVAN, Ginny. Lens on Outdoor Learning. St. Paul, MN: Readleaf Press, 2010.

FERRARO III, Frank M. Enhancement of Convergent Creativity Following a Multiday Wilderness Experience. Ecopsycologie, [s. I.], v. 7, n. 1, p. 7-11, Mar. 2015.

FINCH, Ken; BAILIE, Patti Ensel. Nature Preschools: Putting Nature at the Heart of Early Childhood. Occasional Paper Series, [s. I.], n. 33, 2015

GRANDE, John K. Art nature dialogues: interviews with environmental artists. New York: State University of New York, 2004.

KELLERT, Stephen R. Nature and Childhood Development. In: Building for Life: Designing and Understanding the Human-Nature Connection. London: Island Press, 2005.

LONG, Richard. Walking in circles. London: [s. n.], 1994.

MEDNICK, Sarnoff. The associative basis of the creative process. Psychological Review, [s. l.], v. 69, n. 3, p. 220-232, 1962.

MODESTO, Filipa. A osteologia na arquitectura de Gaudí: Casa Battló, Casa Milá, Parque Guëll, Colonia Guëll e Sagrada Família. 2014. Dissertação (Mestrado em Anatomia Artística) - Faculdade de Belas-Artes, Universidade de Lisboa, [s. I.], 2014.

PLAMBECH, Trine; VAN DEN BOSCH, Cecil C. Konijnendijk. The impact of nature on creativity - A study among Danish creative professionals. Urban Forestry \& Urban Greening, [s. I.], v. 14, n. 2, p. 255-263, 2015. Disponível em: http://dx.doi.org/10.1016/j.ufug.2015.02.006.

SCHIAVONE, Theresa. Grand Canyon Suite. [s. I.], 2000. Disponível em: https://www.npr.org/2000/10/29/1113160/grand-canyon-suite?t=1579090605880\&t=1579177828724. 
SIC NOTÍCIAS. Estudo prova que passar quatro dias na natureza sem tecnologias aumenta a criatividade em 50\%. [s. I.], 2012. Disponível em: https://sicnoticias.pt/vida/2012-12-12-estudo-provaque-passar-quatro-dias-na-natureza-sem-tecnologias-aumenta-criatividade-em-50.

TOVEY, Helen. Playing Outdoors: Spaces and Places, Risk and Challenge. Maidenhead, England: Open University Press, 2007.

WHITE, Randy. Young Children's Relationship with Nature: Its Importance to Children's Development \& the Earth's Future. [S. I.]: White Hutchinson, 2004. Disponível em:

https://www.whitehutchinson.com/children/articles/childrennature.shtml. Acesso em: 25 Out. 2020. 